\title{
Immune response in infants after universal hepatitis B vaccination: a community-based study in Malaysia
}

\author{
Hon Kit $\underline{\text { Cheang }}{ }^{1}$, MD, MRCPCH, Hui Tong Wong ${ }^{2}$, MBBS, Shu Chien $\underline{H o}^{2}$, MBBS, Kee Siang $\underline{C h e w^{2}}$, MBBS,
} Way Seah $L e e^{2,3}$, MBBS, MD

INTRODUCTION This study aimed to assess the immune response in infants who received the three-shot hepatitis B vaccine in Malaysia.

METHODS Consecutive infants born between March 2002 and April 2010 who received three doses of hepatitis B vaccine at a community clinic in Malaysia were enrolled in the study. Screening for hepatitis B surface antigen ( $\mathrm{HBs} A g$ ) and antibody against HBsAg (anti-HBs) was performed after the completion of primary immunisation, at approximately one year of age.

RESULTS A total of 572 infants (median age $9.3 \pm 2.7$ months; range 6.3-48 months) were screened for immune response to hepatitis B vaccination - 553 (96.7\%) infants had adequate levels of anti-HBs ( $\geq 10 \mathrm{IU} / \mathrm{L})$. Of the 440 mothers whose HBsAg status was known, 14 (3.2\%) were positive for HBsAg. None of the 14 infants who were born to HBsAg-positive mothers were positive for HBsAg, and all but one infant had anti-HBs level $\geq 10 \mathrm{IU} / \mathrm{L}$. Gender, gestational age and maternal HBsAg status were not found to significantly affect the subsequent immune response in infants following vaccination.

CONCLUSION The proportion of Malaysian mothers who are positive for HBsAg remains high. The three-shot hepatitis $B$ vaccine, given as part of universal vaccination against hepatitis $B$, provides adequate anti-HBs in the vast majority of infants in a community setting in Malaysia.

Keywords: community, hepatitis $B$ vaccination, immune response

\section{INTRODUCTION}

Hepatitis B virus (HBV) infection remains a global health problem, with more than 350 million people chronically infected with the virus worldwide. ${ }^{(1)}$ Hepatitis $B$ vaccines are effective in preventing HBV infection. In 2009, the World Health Organization (WHO) reported that up to 177 countries had included hepatitis $B$ vaccination into their national infant immunisation programmes. ${ }^{(2)}$ Various studies have shown that immunisation in infancy provides adequate protection against HBV infection, which lasts even till school-going age. ${ }^{(3)}$ However, studies have also found that not every recipient of the vaccine produces adequate protective levels of the antibody after completion of primary immunisation. ${ }^{(4)}$

In Malaysia, universal hepatitis B vaccination of all newborn infants has been implemented since 1989. However, to the authors' knowledge, only one industry-sponsored study has ever assessed the seroprotective anti-hepatitis B antibody (anti-HBs) levels in a setting where hepatitis B vaccines were given in combination with other childhood vaccines. ${ }^{(5)}$ The efficacy of the universal hepatitis B vaccination programme has never been assessed in a community setting in Malaysia. The aim of the present study was to assess the immune response of newborns who received the three-shot hepatitis $B$ vaccine at community child health clinics in Malaysia, by measuring their anti-HBs levels after immunisation at approximately one year of age.

\section{METHODS}

The present study was conducted among infants who attended the child health clinic at Lam Wah Ee Hospital (LWEH), a charitable hospital that caters mainly to the lower-to-middle income population in Penang, Malaysia. The study was approved by the institutional ethics review committee.

Consecutive newborn infants delivered at LWEH between March 2002 and April 2010 (study period, 8 years 2 months), who were managed by a single clinician, were screened for antiHBs levels after the completion of their primary immunisation, at approximately one year of age. All newborn infants were given the three-shot hepatitis $B$ vaccine at birth, one month and six months of age. Prior to 2002, the hepatitis B vaccine given at LWEH was Hepavax-Gene (Crucell, Leiden, The Netherlands), while that given after 2002 was Engerix- ${ }^{\circledR}$ (GlaxoSmithKline Biologicals, Rixensart, Belgium). Infants delivered to mothers who were positive for hepatitis B surface antigen (HBsAg) were additionally given anti-hepatitis B immunoglobulin (Hepabig ${ }^{\circledR}$; VHB Life Sciences, Mumbai, India) within 24 hours of birth.

Screening for anti-HBs levels was performed at approximately one year of age. Adequate protective level of anti-HBs was defined as antibody level $\geq 10 \mathrm{IU} / \mathrm{L}$. ${ }^{(6)}$ Screenings for HBsAg and anti-HBs were performed using chemiluminescent microparticle immunoassay techniques (Abbott Architect ci8200 Analyser; Abbott Diagnostics, Abbott Park, IL, USA).

${ }^{1}$ Paediatric Unit, Lam Wah Ee Hospital, Penang, ${ }^{2}$ Department of Paediatrics, University Malaya Medical Centre, ${ }^{3}$ Paediatric and Child Health Research Group, University of Malaya, Kuala Lumpur, Malaysia

Correspondence: Prof Way Seah Lee, Professor and Head, Department of Paediatrics, University Malaya Medical Centre, Kuala Lumpur 59100, Malaysia. leews@um.edu.my 
Table I. Immune response to hepatitis B vaccination in Malaysian infants $(n=572)$.

\begin{tabular}{|c|c|c|c|}
\hline \multirow[t]{2}{*}{ Variable } & \multicolumn{2}{|c|}{ No. of infants (\%) } & \multirow[t]{2}{*}{ p-value } \\
\hline & $\begin{array}{c}\text { Antibody level } \\
\geq 10 \mathrm{IU} / \mathrm{L}(\mathrm{n}=553)\end{array}$ & $\begin{array}{c}\text { Antibody level } \\
<10 \mathrm{IU} / \mathrm{L}(\mathrm{n}=19)\end{array}$ & \\
\hline Gender & & & 0.15 \\
\hline Male & $290(52.4)$ & $14(73.7)$ & \\
\hline Female & $263(47.6)$ & 5 (26.3) & \\
\hline Gestational age & & & 0.26 \\
\hline Term & $485(87.7)$ & 18 (94.7) & \\
\hline Preterm & $58(10.5)$ & $1(5.3)$ & \\
\hline Unknown & $10(1.8)$ & $0(0)$ & \\
\hline $\begin{array}{l}\text { Maternal HBsAg } \\
\text { status }\end{array}$ & & & 0.50 \\
\hline Positive & $13(2.4)$ & $1(5.3)$ & \\
\hline Negative & $412(74.5)$ & $14(73.7)$ & \\
\hline Unknown & $128(23.1)$ & $4(21.1)$ & \\
\hline
\end{tabular}

HBsAg: hepatitis B surface antigen

\section{RESULTS}

A total of 572 consecutive infants, delivered between March 2002 and April 2010 at LWEH, who received the three-shot hepatitis $B$ vaccine, were screened for immune response to hepatitis B vaccination (Table I). Of these, 304 (53.1\%) infants were male. The ethnicities of the infants were: $283(49.5 \%)$ Chinese, 143 (25.0\%) Malay, 140 (24.5\%) Indian, and 6 (1.0\%) minor ethnicities. A majority of infants ( $n=503,88.0 \%$ ) were delivered at term (gestational age $\geq 37$ completed weeks). A total of $426(74.5 \%)$ mothers were HBsAg negative, while 14 (2.4\%) were $\mathrm{HBsAg}$ positive. Among women with known $\mathrm{HBsAg}$ status ( $\mathrm{n}=440), 14(3.2 \%)$ were HBsAg-positive. The HBV status of $132(23.0 \%)$ women was unknown. All 572 infants received the first dose of hepatitis B vaccine at birth. However, only 506 $(88.5 \%)$ and $551(96.3 \%)$ infants had a record of receiving the second and third dose of the vaccine, respectively, at LWEH. Screening for anti-HBs was performed at a median age of $9.3 \pm 2.7$ (range 6.3-48) months.

Among the 572 infants, 19 (3.3\%) had inadequate antibody response - anti-HBs antibody was not detected in $3(0.5 \%)$ infants, while antibody levels were $<10 \mathrm{IU} / \mathrm{L}$ for another 16 (2.8\%) infants. Among the remaining 553 (96.7\%) infants who had antibody levels $\geq 10 \mathrm{IU} / \mathrm{L}, 310$ (54.2\%) had antibody levels $>1,000 \mathrm{IU} / \mathrm{L}$. Factors such as gender, gestational age and maternal HBsAg status were not found to significantly affect the subsequent anti-HBs antibody levels in infants receiving hepatitis B vaccination (Table I). The majority of infants (13/14) delivered to HBsAg-positive mothers had adequate antibody levels. None of the infants in our group was found to be HBsAg-positive.

\section{DISCUSSION}

Universal hepatitis B vaccination is known to bring enormous benefits to communities where HBV infection is endemic. ${ }^{(1)}$ Hepatitis $B$ vaccination has been associated with the elimination or reduction of childhood hepatocellular carcinoma, ${ }^{(7)}$ acute liver failure ${ }^{(8)}$ and, more recently, virus-associated membranous nephropathy. ${ }^{(9)}$ Universal hepatitis B immunisation of newborns has been implemented in Malaysia since 1989. ${ }^{(10)}$ Since then, there has been a steady decline in the seroprevalence of $\mathrm{HBsAg}$ - from 2.5\% for children born in 1985 (four years before universal immunisation) to $0.4 \%$ among school children born in 1996. ${ }^{(10)}$

The results of the present study show that universal hepatitis B vaccination of newborns in Malaysia is highly successful. $96.7 \%$ of the 572 infants immunised in our study were found to have adequate levels of anti-HBs at approximately one year of age. Furthermore, none of the 14 infants who were born to HBsAgpositive mothers were found to be $\mathrm{HBsAg}$-positive. Among these 14 infants, 13 were found to have adequate levels of protective anti-HBs following immunisation. Failure to produce detectable antibody levels even after three doses of hepatitis B vaccines has been reported in a small minority of patients. ${ }^{(11)}$ Researchers have adopted various methods to overcome this problem, including administering a fourth dose of vaccine ${ }^{(11)}$ or a booster dose at a later age. ${ }^{(3)}$ However, it should be noted that the risk of acquiring HBV infection among non-responders has been found to be similar to that among those given booster vaccines. $^{(3)}$

The present study also found that chronic HBV infection remains high among Malaysian mothers, with 3.2\% of women whose HBsAg status was known testing positive for HBsAg. This underscores the importance of universal hepatitis $B$ vaccination. We expect that the proportion of HBsAg-positive women will dramatically decrease as the cohort of Malaysian women who received universal hepatitis B vaccination (introduced in 1989) enters reproductive age. However, for women who had not been immunised, screening at antenatal clinics for $\mathrm{HBsAg}$ remains an important strategy for reducing vertical transmissions. ${ }^{(12)}$

One of the potential drawbacks of the present study was the lack of information on the status of hepatitis B e antigen (HBeAg) among women who were HBsAg positive, as it is well known that vertical transmission is more likely to occur among infants born to women who are positive for both $\mathrm{HBeAg}$ and $\mathrm{HBsAg} .{ }^{(12)}$

In conclusion, the proportion of Malaysian mothers who are positive for $\mathrm{HBsAg}$ remains high. Our results suggest that universal vaccination of newborns with three doses of hepatitis $B$ vaccine in a community clinic setting in Malaysia has proven highly successful in preventing the perinatal transmission of $\mathrm{HBV}$ infection, as well as achieving adequate protective levels of anti-HBs in a vast majority of infants.

\section{REFERENCES}

1. Huang LM, Lu CY, Chen DS. Hepatitis B virus infection, its sequelae, and prevention by vaccination. Curr Opin Immunol 2011; 23:237-43.

2. World Health Organization. Immunization, vaccines and biologicals [online]. Availableat:http://www.who.int/immunization/topics/hepatitis_b/ en/index.html. Accessed September 1, 2011.

3. Shih $\mathrm{HH}, \mathrm{Chang} \mathrm{MH}, \mathrm{Hsu} \mathrm{HY}$, etal. Long term immune response of universal hepatitis B vaccination in infancy: a community-based study in Taiwan. Pediatr Infect Dis J 1999; 18:427-32. 
4. Rosado MM, Scarsella M, Pandolfi E, et al. Switched memory B cells maintain specific memory independently of serum antibodies: the hepatitis B example. Eur J Immunol 2011; 41:1800-8.

5. Wong SL, Soosai P, Teoh YL, et al. Four is better than nine: a combined diphtheria-tetanus-pertussis-hepatitis B-Haemophilus influenza type b vaccine for routine immunization in Malaysia. Southeast Asian J Trop Med Public Health 2008; 39:474-83.

6. Jack AD, Hall AJ, Maine N, Mendy M, Whittle HC. What level of hepatitis B antibody level is protective? J Infect Dis 1999; 179:489-92.

7. McMahon BJ, Bulkow LR, Singleton RJ, et al. Elimination of hepatocellular carcinoma and acute hepatitis B in children 25 years after a hepatitis B newborn and catch-up immunization program. Hepatology 2011; 54:801-7.

8. Chen HL, Chang CJ, Kong MS, et al. Pediatric fulminant hepatic failure in endemic areas of hepatitis B infection: 15 years after universal hepatitis B vaccination. Hepatology 2004; 39:58-63.

9. Liao MT, Chang MH, Lin FG, et al. Universal hepatitis B vaccination reduces childhood hepatitis $B$ virus-associated membranous nephropathy. Pediatrics 2011; 128:e600-4.

10. $\mathrm{Ng} \mathrm{KP}$, Saw TL, Baki A, et al. Impact of the expanded program of immunization against hepatitis $B$ infection in school children in Malaysia. Med Microbiol Immunol 2005; 194:163-8.

11. Jafarzadeh A, Zarei S, Shokri F. Low dose revaccination induces robust protective anti-HBs antibody response in the majority of healthy nonresponder neonates. Vaccine 2008; 26:269-76.

12. Chen HL, Lin LH, Hu FC, et al. Effects of maternal screening and universal immunization to prevent mother-to-infant transmission of HBV. Gastroenterology 2012; 142:773-781.e2.

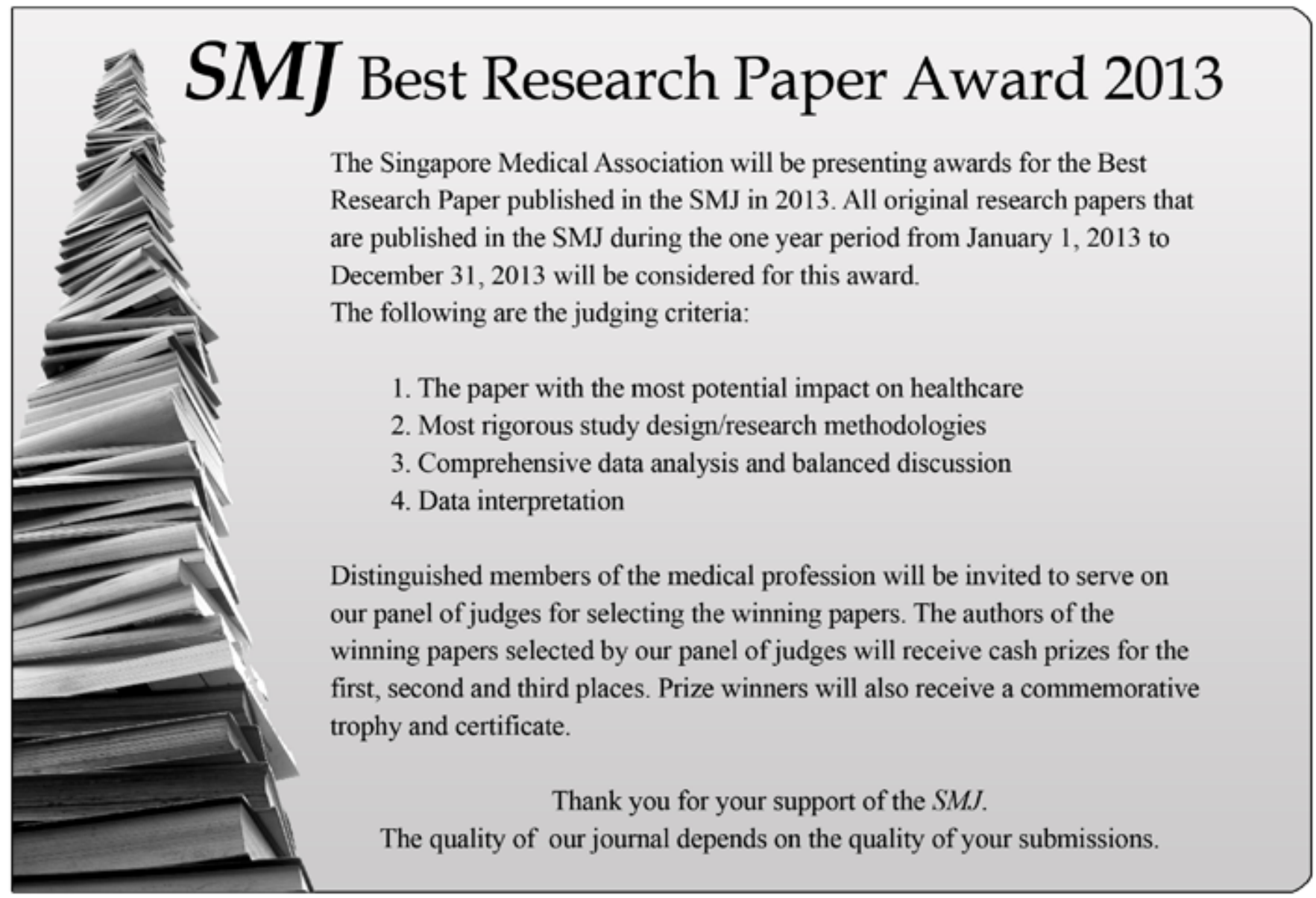

